\title{
Glycine Substitution Reduces Antimicrobial Activity and Helical Stretch of diPGLa-H in Lipid Micelles
}

\author{
M.-A. Sani ${ }^{*_{1}}$, C. Saenger ${ }^{1}$, D. Juretic ${ }^{2}$ and F. Separovic ${ }^{*_{1}}$ \\ 'School of Chemistry, Bio21 Institute, University of Melbourne, VIC 3010, Australia \\ ${ }^{2}$ Mediterranean Institute for Life Sciences, Split, Croatia

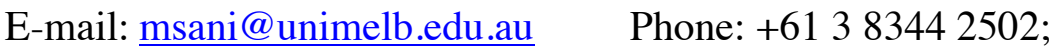

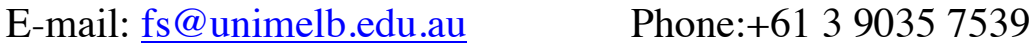




\begin{abstract}
With the rise in antibiotic resistance, antimicrobial peptides (AMPs) show promise for therapeutic development but higher specificity is required. PGLa-H is a naturally occurring decapeptide, reported to have moderate antibacterial activity and low hemolytic activity, with its sequence being identical to the C-terminal fragment of highly selective AMP, PGLa. DiPGLa-H, a sequential tandem repeat of PGLa-H, as well as Kiadin, an analogue with a Val to Gly substitution at position 15 , display improved in vitro bactericidal activity against both Gram-negative and Gram-positive pathogens, with generally low toxicity for human cells. Despite Gly being a more flexible residue, NMR structural studies showed little difference in structure and dynamics between the two peptides for the first 14 residues, with somewhat greater flexibility in the C-terminus of Kiadin resulting in a tighter structure of the peptide in the presence of sodium dodecyl sulfate micelles. AMPs found in organisms often exhibit minimal amino acid mutations and such small differences in peptide conformation may be utilized to design more selective AMPs.
\end{abstract}




\section{Introduction}

Increasing bacterial resistance to antibiotics is becoming a serious problem. However, the natural evolution of host defence peptides over millions of years has maintained their capacity to protect the host organisms against microbial infection. These antimicrobial peptides (AMPs) usually are cationic and membrane-active so that it is more difficult for bacteria to evolve permanent resistance. Although they display some selectivity for bacterial over eukaryotic membrane, AMPs are often toxic to host cells at concentrations not greatly higher than antibacterial dosages. Thus, a better understanding of their mode of action to control of cell selectivity and toxicity is necessary in order to move towards clinical applications '. Hence, there is a need to identify AMPs that are more active against multiresistant pathogens but less toxic against human cells.

Small, linear AMPs are widely distributed in Nature and are natural candidates as potential antibiotics. Anuran AMPs, in particular magainin-2 and PGLa, have been well studied and we also have studied AMPs from Australian tree frogs. PGLa is a highly selective cationic AMP originally isolated from the frog Xenopus laevis ${ }^{2}$. The 10 residue C-terminal fragment, PGLa-H, of PGLa also isolated from the African clawed frog as a naturally occurring peptide, is reported to have moderate in vitro activity against both Gram-negative and Gram-positive bacteria and low hemolytic activity ${ }^{3}$. An AMP based on a sequential tandem repeat, diPGLa$\mathrm{H}$, was designed to increase its activity with a rationale that 20 residues, when in helical conformation, can span the cytoplasmic membrane with a potential for cooperative pore formation and bactericidal activity in a similar manner as PGLa ${ }^{4}$. Note, however, that PGLa is mainly found parallel to the membrane surface in unsaturated lipid bilayers but adopts a tilted orientation in the membrane at high peptide to lipid ratio and in saturated lipid bilayers s. An algorithm to predict the selectivity index (SI, in terms of $\mathrm{HC}_{\text {so }} / \mathrm{MIC}$ for E. coli) of anuran 
peptides based on hydrophobicity plots and activity relationships indicated that the designed AMP (diPGLa-H) would have an acceptable SI value ${ }^{\circ}$. The same algorithm suggested a possible substitution of Valis by Gly would further improve selectivity resulting in the peptide, Kiadin, with sequence KIAKV ALKAL KIAKG ALKAL-NH ${ }_{2}$. Molecular dynamics simulations also indicated a reduced stability of the helix for Kiadin due to the Gly substitution ?

Gly residues are known to be a more flexible residues and act as a helix breaker. Our earlier NMR work with the AMP maculatin 1.1 (Mac) showed that although the peptides had a similar structure, the extent of bilayer disordering followed the order Mac P15G < Mac P15A $<$ Mac ${ }^{8}$. Replacing Pro in native Mac with Ala induced a tighter $\alpha$-helix that lacks the significant kink of the native peptide and a redistribution of residues so that the amphipathicity is altered. An increase in hemolytic activity occurs and the Pro-to-Ala replacement resulted in a 5- to 10 -fold decrease in antimicrobial activity. Mac P15G is more flexible than native Mac but likely to adopt some degree of kink structure given the flexibility of the Gly residue. Given that Mac P15A was the least active peptide of the three, then possibly Kiadin with the Gly substitution at Val's, may show improved antimicrobial activity relative to diPGLa-H.

The diPGLa-H and Kiadin peptides were synthesized and tested for in vitro activity against a range of bacteria and fungus, as well as for cytotoxicity. The peptide structures in lipid micelles were compared by CD and NMR spectroscopy to gain insight into differences in structure-activity relationships. 


\section{Material and Methods}

The peptides diPGLa-H and Kiadin were obtained from Mimotopes (Melbourne, Australia) at a purity of greater than $90 \%$ and used without further purification. Colistin-sulfate, vancomycin- $\mathrm{HCl}$, fluconazole, deuterated water $\left(\mathrm{D}_{2} \mathrm{O}\right)$, deuterated sodium dodecyl sulfate $\left(\mathrm{d}_{25}-\mathrm{SDS}\right)$ were purchased from Sigma-Aldrich (Sydney, Australia). All bacterial and fungi strains are repository of CO-ADD (Community for Antimicrobial Drug Discovery, University of Queensland, Australia).

\section{Minimum inhibition concentration assays (MIC)}

Solutions of diPGLa-H and Kiadin were prepared in DMSO and water and plated in duplicate as a 2-fold dose response from 32 to $0.25 \mu \mathrm{g} / \mathrm{mL}$ (or 20 to $0.156 \mu \mathrm{M}$ ), with a maximum of 0.5\% DMSO in 384-well, non-binding surface plate (NBS) for each bacterial/fungal strain. Colistin and vancomycin were used as positive bacterial inhibitor standards for Gramnegative and Gram-positive bacteria, respectively. Fluconazole was used as a positive fungal inhibitor standard for C. albicans and C. neoformans. The antibiotics were provided in four concentrations, with two above and below its MIC value as duplicates. All the sample preparations were done using liquid handling robots.

All bacteria were cultured in cation-adjusted Mueller Hinton broth (CAMHB) at $37^{\circ} \mathrm{C}$ overnight. A sample of each culture was then diluted 40-fold in fresh broth and incubated at $37^{\circ} \mathrm{C}$ for $1.5-3 \mathrm{~h}$. The resultant mid-log phase cultures were diluted (CFU/mL measured by $\mathrm{OD}_{\text {oro }}$ ), then added to each well of the compound containing plates, giving a cell density of $5 \times 10^{5} \mathrm{CFU} / \mathrm{mL}$ and a total volume of $50 \mu \mathrm{L}$. All the plates were covered and incubated at $37^{\circ} \mathrm{C}$ for $18 \mathrm{~h}$ without shaking. 
Inhibition of bacterial growth was determined by measuring absorbance at $600 \mathrm{~nm}\left(\mathrm{OD}_{\text {юю }}\right)$, using a Tecan M1000 plate reader (Morrisville, NC). The percentage of growth inhibition was calculated for each well, using the negative control (media only) and positive control (bacteria without inhibitors) on the same plate as references. The significance of the inhibition values was determined by modified Z-scores, calculated using the median and median absolute deviation (MAD) of the samples (no controls) on the same plate. Samples with inhibition value above $80 \%$ and $\mathrm{Z}$-score above 2.5 for either replicate $(\mathrm{n}=2$ on different plates) were classed as actives. Samples with inhibition values between 50 - 80\% and Z-score above 2.5 for either replicate ( $\mathrm{n}=2$ on different plates) were classed as partial actives.

\section{Antifungal assay}

Fungi strains were cultured for three days on Yeast Extract-Peptone Dextrose (YPD) agar at $30^{\circ} \mathrm{C}$. A yeast suspension of $1 \times 10^{\circ}$ to $5 \times 10^{\circ} \mathrm{CFU} / \mathrm{mL}$ (as determined by $\mathrm{OD}_{580}$ ) was prepared from five colonies. The suspension was subsequently diluted and added to each well of the compound-containing plates, giving a final cell density of fungi suspension of $2.5 \times 10^{3}$ $\mathrm{CFU} / \mathrm{mL}$ and a total volume of $50 \mu \mathrm{L}$. All plates were covered and incubated at $35^{\circ} \mathrm{C}$ for $24 \mathrm{~h}$ without shaking.

Growth inhibition of $C$. albicans was determined measuring absorbance at $530 \mathrm{~nm}\left(\mathrm{OD}_{5: 0}\right)$, while the growth inhibition of $C$. neoformans was determined measuring the difference in absorbance between 600 and $570 \mathrm{~nm}\left(\mathrm{OD}_{\text {600:50 }}\right)$, after the addition of resazurin $(0.001 \%$ final concentration) and incubation at $35^{\circ} \mathrm{C}$ for additional $2 \mathrm{~h}$. The absorbance was measured using a Biotek Synergy HTX plate reader (Winooski, VT). The percentage of growth inhibition was calculated for each well, using the negative control (media only) and positive control (fungi without inhibitors) on the same plate. The significance of the inhibition values was 
determined by modified Z-scores, calculated using the median and MAD of the samples (no controls) on the same plate. Samples with inhibition value above $80 \%$ and Z-score above 2.5 for either replicate ( $\mathrm{n}=2$ on different plates) were classed as actives. Samples with inhibition values between $50-80 \%$ and Z-score above 2.5 for either replicate ( $\mathrm{n}=2$ on different plates) were classed as partial actives.

\section{Cytotoxicity assay}

HEK293 cells were counted manually in a Neubauer hemocytometer and then plated in the 384-well plates in duplicate containing the compounds to give a density of 6000 cells/well in a final volume of $50 \mu \mathrm{L}$. Dulbecco's Modified Eagle's medium supplemented with $10 \%$ Fetal Bovine Serum was used as growth media and the cells were incubated together with the compounds for $20 \mathrm{~h}$ at $37^{\circ} \mathrm{C}$ in $5 \% \mathrm{CO}_{2}$. Cytotoxicity (or cell viability) was measured by fluorescence, ex: 560/10 nm, em: 590/10 nm (F560/590), after addition of $5 \mu \mathrm{L}$ of $25 \mu \mathrm{g} / \mathrm{mL}$ Resazurin $\left(2.3 \mu \mathrm{g} / \mathrm{mL}\right.$ final concentration) and after incubation for further $3 \mathrm{~h}$ at $37^{\circ} \mathrm{C}$ in $5 \%$ $\mathrm{CO}_{2}$. The fluorescence intensity was measured using a Tecan M1000 Pro plate reader, using automatic gain calculation. $\mathrm{CC}_{50}$ (concentration at $50 \%$ cytotoxicity) were calculated by curve fitting the inhibition values $v s$. $\log$ (concentration) using sigmoidal dose-response function, with variable fitting values for bottom, top and slope.

\section{Circular dichroism $(C D)$}

Appropriate volumes of diPGLa-H, Kiadin and SDS stock solutions in phosphate buffer (10 $\mathrm{mM}$ phosphate, $1 \mathrm{mM} \mathrm{KCl}, \mathrm{pH}$ 7.4) were mixed to produce $300 \mu \mathrm{L}$ samples with lipid to peptide $(\mathrm{L} / \mathrm{P})$ molar ratio of $150: 1$ and a final SDS concentration of $7.5 \mathrm{mM}(\mathrm{CMC} \sim 6 \mathrm{mM})$. Samples were allowed to equilibrate at $298 \mathrm{~K}$ or $323 \mathrm{~K}$ for 10 mins prior to measurements. CD spectra were acquired on a Chirascan spectropolarimeter (Applied Photophysics Ltd, 
UK) between 190 and $250 \mathrm{~nm}$ using a $1 \mathrm{~mm}$ pathlength quartz cell (Helma). Spectra were acquired with $1 \mathrm{~nm}$ data intervals, $0.5 \mathrm{~s}$ integration time and 5 scans accumulation. Signal was recorded as milli-degrees. Spectra were zeroed at $250 \mathrm{~nm}$ and normalised to give units of mean-residue ellipticity (MRE) according to

$$
[\theta]_{M R E}=\theta /\left(c \times l \times N_{R}\right)
$$

where $\theta$ is the recorded ellipticity in milli-degrees, $\mathrm{c}$ is the peptide concentration in $\mathrm{dmol} / \mathrm{L}, 1$ is the cell path-length in $\mathrm{cm}$, and $\mathrm{N}_{r}$ is the number of residues per peptide.

\section{Nuclear magnetic resonance (NMR)}

NMR samples were prepared by dissolving the dry peptides in $150 \mathrm{mM}$ sodium dodecyl- $\mathrm{d}_{25}$ sulfate (20 mM phosphate $\mathrm{pH} 7.4,50 \mathrm{mM} \mathrm{KCl}, 0.05 \mathrm{mM} \mathrm{DSS}, 10 \% \mathrm{v} / \mathrm{v} \mathrm{D}_{2} \mathrm{O}$ ) to reach a final peptide concentration of $2 \mathrm{mM}$. NMR spectra were obtained at $323 \mathrm{~K}$ on a $800 \mathrm{MHz}$ Bruker Advance II equipped with a TCI cryoprobe. Chemical shifts were referenced to DSS $(4,4-$ dimethyl-4-silapentane-1-sulfonic acid) at $0 \mathrm{ppm}$. Data were processed in Topspin (Bruker) and analysed using the CCPNmr Analysis program (Laue 2005 Proteins 59, 687). Backbone and side chains were assigned using 'H homonuclear COSY, TOCSY (mixing time $\tau_{\text {mix }}=80$ $\mathrm{ms})$ and $\operatorname{NOESY}\left(\tau_{\text {mix }}=150,200,300 \mathrm{~ms}\right)$ experiments.

\section{Structure calculations}

The NOESY cross-peak assignments were subsequently used to generate distance restraints for the structure determination. The NOE distance restraints were supplemented with dihedral angle restraints predicted with DANGLE from $\mathrm{H} \alpha$ chemical shifts. A standard CNS 1.1based protocol was employed using the ARIA 2.2 interface. 10 lowest energy structures were refined in a water shell and evaluated with MolProbity. 


\section{Results and Discussion}

Valine to glycine substitution reduced antibacterial activities

The substitution of valine for glycine at position 15 produced minor differences in antimicrobial activities against both Gram-negative and Gram-positive bacteria and fungi, but overall Kiadin was less potent than diPGLA-H. While the MIC against A. baumannii remained very promising independently of the substitution $(1 \mu \mathrm{g} / \mathrm{ml})$, both peptides were inactive against the Gram-negative P.aeruginosa, the fungus $C$. albicans and were also noncytotoxic against human kidney cells (Table 1). Previous work showed that both peptides are non-hemolytic, with Kiadin being slightly less hemolytic than diPGLa-H ${ }^{\prime}$ and we saw no hemolysis up to $32 \mu \mathrm{g} / \mathrm{ml}$ for neither peptide.

Interestingly, diPGLa-H was eight-fold more potent against multi-resistant $S$. aureus (MRSA) and two-fold against the multidrug resistant $K$. pneumonia than Kiadin, and thus structural investigations were performed to identify if the valine to glycine substitution induced a noticeable change in the secondary structure of diPGLa-H.

\begin{tabular}{lcc}
\hline \hline \multicolumn{1}{l}{ Table 1. Bactericidal, antifungal and cytotoxic activitiesof diPGLa-H and Kiadin } \\
\hline \hline & $\begin{array}{c}\text { diPGLa-H } \\
(\mu \mathrm{g} / \mathrm{ml})\end{array}$ & $\begin{array}{c}\text { Kiadin } \\
(\mu \mathrm{g} / \mathrm{ml})\end{array}$ \\
MIC & 2 & 3 \\
E. coli ATCC 25922 & 2 & 16 \\
K. pneumonia ATCC 700603 (MDR) & 8 & 1 \\
A. baumannii ATCC 19606 & 1 & $>32$ \\
P. aeruginosa ATCC 27853 & $>32$ & 16 \\
S. aureus ATCC 43300 (MRSA) & 2 & $>32$ \\
C. albicans ATCC 90028 & $>32$ & 6 \\
C. neoformans ATCC 208821 & 4 & $>32$ \\
Cytotoxicity & $>32$ & \\
HEK293 (human kidney cell) & & \\
\hline \hline
\end{tabular}




\section{Kiadin and diPGLa-H produced similar CD lineshape}

The CD spectra of Kiadin and diPGLa-H in buffer were typical of random coil structures with a single minimum at $198 \mathrm{~nm}$ (Fig. 1). The presence of SDS micelles induced a transition from random coil to helical structures as indicated by the two minima at $222 \mathrm{~nm}$ and $209 \mathrm{~nm}$ and a maximum at $192 \mathrm{~nm}$. The experiments performed at $298 \mathrm{~K}$ showed slightly higher intensities than at $323 \mathrm{~K}$, especially for Kiadin, but overall the CD experiments did not show any significant difference in secondary structure content between both peptides, as previously reported '. Glycine is often reported as a helix-breaking residue due to its large conformational space of phi-psi angles and thus increased entropy of the backbone in the coil structure ${ }^{9}$. However, in these peptide sequences and within the resolution associated with CD, it was not possible to determine if significant structural modification had occurred. Highresolution structures were thus investigated by solution NMR of the peptides in SDS micelle environments.
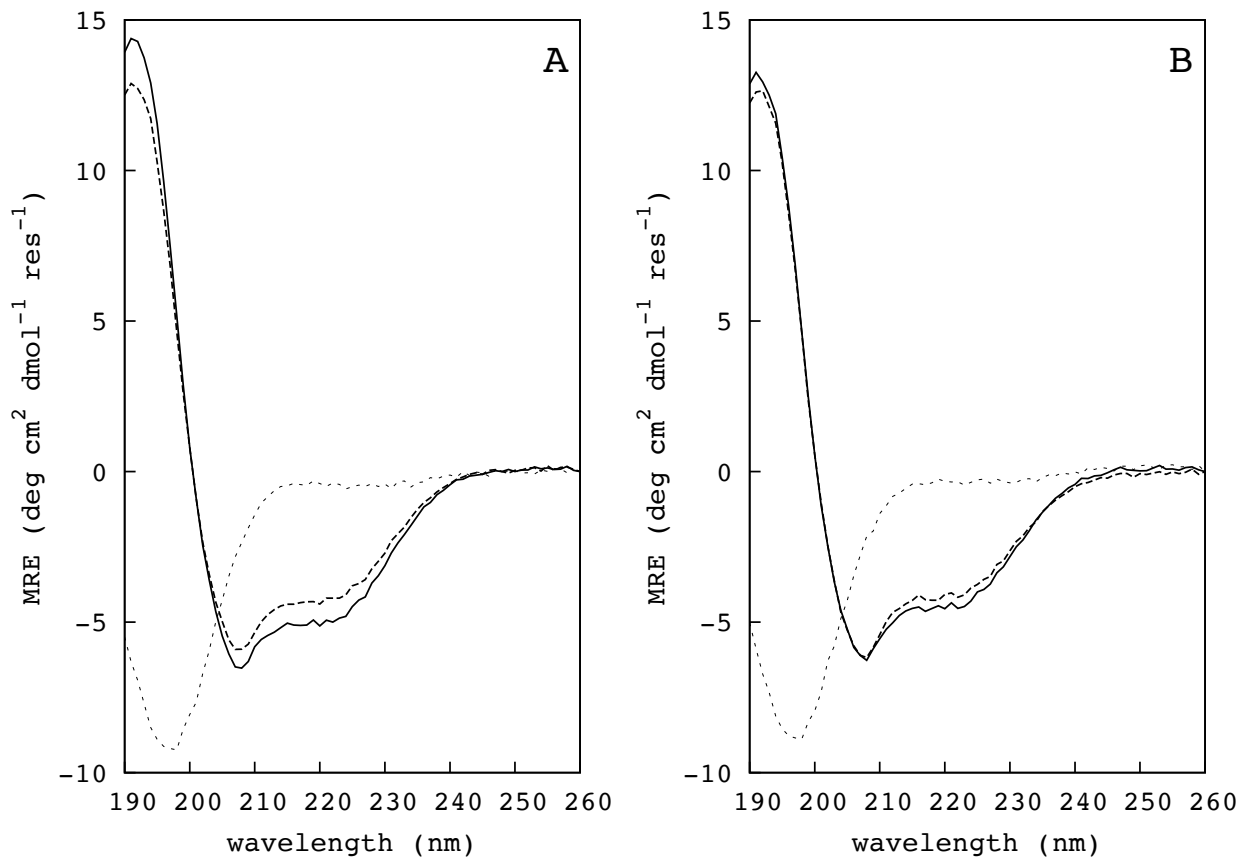
Figure $1 \mathrm{CD}$ spectra of $50 \mu \mathrm{M}$ (A) Kiadin, and (B) diPGLa-H peptides in buffer (dotted lines) and in the presence of $150 \mathrm{mM}$ SDS micelles at (solid line) $298 \mathrm{~K}$ and (dashed line) $323 \mathrm{~K}$. Five scans were averaged and appropriate background subtracted.

Glycine substitution induced a change in helical pitch as revealed by solution NMR

The 3D structures of the diPGLa-H and Kiadin peptides in SDS micelles were determined by using 'H, homonuclear ${ }^{\prime} \mathrm{H}-\mathrm{-} H$ and heteronuclear ${ }^{15} \mathrm{~N}-{ }^{-} \mathrm{H}$ HSQC NMR spectroscopy. The resonance assignments were achieved using standard protocols ${ }^{{ }^{\circ}}$. Briefly, TOCSY and COSY experiments were used to determine the intra-residue hydrogen resonances and thus the spin systems. The sequential walk was then performed using the NOESY spectra (Supp. Info. Fig. $\mathrm{S} 1$ and Fig. S2), starting from the well-identified C-amidated residue $\left({ }^{20} \mathrm{Leu}-\mathrm{NH}_{2}\right)$. It is noteworthy that residues Lys and Ile did not produce backbone amide proton resonances, most likely due to fast exchange process on the NMR time scale. The presence of $\alpha \mathrm{N}(\mathrm{i}, \mathrm{i}+2)$, $\alpha \mathrm{N}(\mathrm{i}, \mathrm{i}+3), \alpha \mathrm{N}(\mathrm{i}, \mathrm{i}+4)$ and $\alpha \beta(\mathrm{i}, \mathrm{i}+3)$ NOEs confirmed that the peptides were predominantly in a helical conformation. However, one $\mathrm{NN}(\mathrm{i}, \mathrm{i}+2)$ found for ${ }^{18} \mathrm{Lys}$ of Kiadin suggested a smaller helical pitch, as found in $3_{10}$ helical conformation (Fig. 2, left and middle panels). The ${ }^{15} \mathrm{~N}$ chemical shifts of diPGLa-H and Kiadin were obtained from the ${ }^{\text {i5 }} \mathrm{N}-\mathrm{H}$ HSQC (Supp. Info. Fig. S3), using the 'H chemical shift assigned through the TOCSY and NOESY experiments, and applied to restrain further the dihedral angles for structure calculation ".

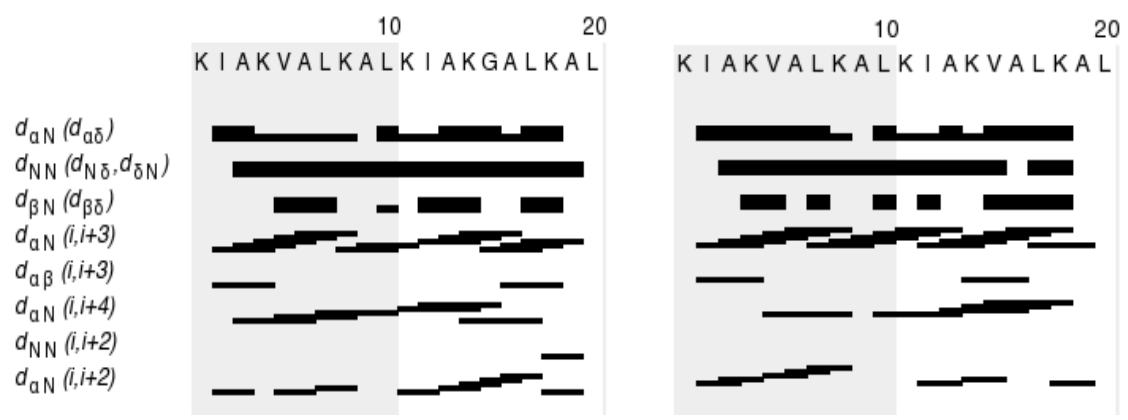


Figure 2 Sequential and medium-range NOEs in SDS micelles of: (left panel) Kiadin, and (right) diPGLa-H.

Ensembles of 10 lowest energy structures refined in a water shell of diPGLa-H and Kiadin displayed a single helical stretch for both peptides (Fig. 3), which is consistent with that previously reported for PGLa ${ }^{12}$. The quality and statistical analysis of the structures are listed in Table S2, and showed no dihedral violation and one minor distance violation for Kiadin, involving the flexible N-terminus, and none for diPGLa-H. The backbone root mean square deviations (RMSDs) of the mean structures were $0.47 \AA$ and $0.52 \AA$ for diPGLa-H and Kiadin, respectively. The hydrophobic surfaces were calculated based on the Kyte and Doolittle scale ${ }^{13}$ and showed that both peptides possess an amphipathic nature in the presence of a membrane-mimicking interface, with the lysines almost all aligned on one side and the hydrophobic residues on the other side of the helical conformation (Fig. 3).

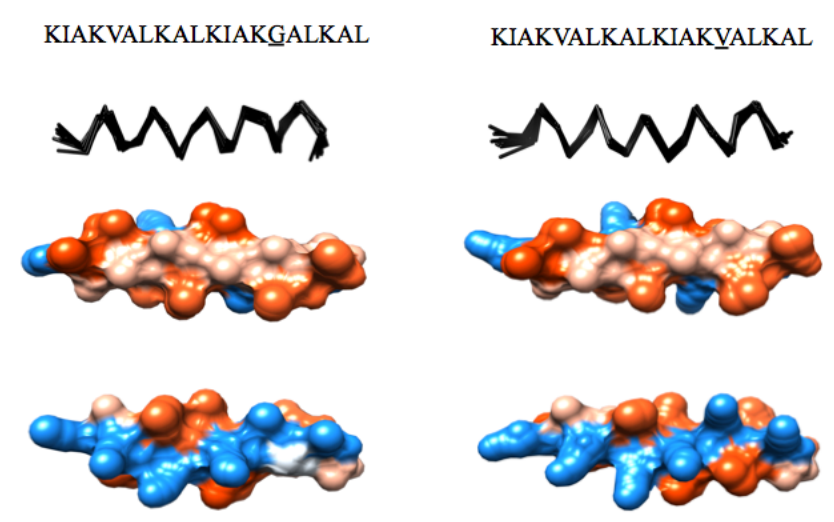

Figure 3 Ten lowest energy NMR structures of Kiadin (left), and diPGLa-H (right) superimposed to give best pairing match. The hydrophobic surfaces according the Doolittle scale of the average structure are shown below the NMR structures with the following colour code: blue (most hydrophilic), white (neutral), and orange (most hydrophobic). 
The membrane-disrupting activity of most AMPs have been attributed to their ability to form amphipathic structures, which allow the peptide to partially insert into membrane bilayers and allow water to disrupt the lipid acyl chain packing ${ }^{14.15}$. Furthermore, the composition of lipid membranes has been shown to greatly influence the random coil to helical transition ${ }^{16}$ and peptide insertion into the hydrophobic core of the bilayer ${ }^{17}$, which in turn modulates the antibacterial activity of AMPs ${ }^{18}$. In fact, PGLa has been shown to preferentially accumulate at the lipid-water interface of negatively charged versus neutral membranes, mainly due to electrostatic interactions, and induce small perturbations in the dynamics of lipid headgroup and acyl chain regions ${ }^{19}$. The peptide structures, however, were obtained in a highly-curved micelle environment which can result in curved peptide structures ${ }^{20}$. However, diPGLa-H and Kiadin did not exhibit any significant curvature, which could indicate either a partial insertion of the hydrophobic interface of the peptides into the micelle interior rather than curving over the micelle surface or the detergent molecules reorganizing so as to accommodate the peptide.

The average of the 10 lowest energy structures was used to compare diPGLa-H and Kiadin helical structures (Fig. 4). The most significant structural difference is located from around residue 15 onward, for which Kiadin exhibited a tighter helical pitch.

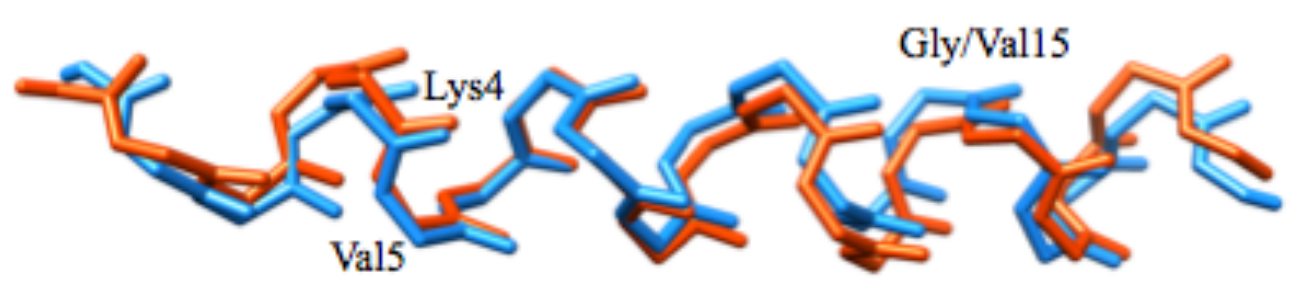

Figure 4 Average structures of 10 lowest energy structures of Kiadin (orange) and diPGLa-H (blue) superimposed using the best pair matching. 
Comparison of the $\mathrm{H} \alpha$ chemical shifts compared to those found for a random coil conformation ${ }^{21}$ indicated that both peptides adopted a long helical stretch; however, Kiadin exhibited a break at "Gly (Fig. 5A). NH chemical shift difference from random coil values ${ }^{22}$ showed an increase in differentiation between diPGLa-H and Kiadin starting at residue "Lys. The NH chemical shift of Kiadin appeared mainly downfield compared to diPGLa-H (Fig. 5B), which may indicate a stronger bonding to the backbone carbonyl ${ }^{23}$, but $\mathrm{NH}$ chemical shift are not reliable to unambiguously distinguish random coil to helical structure ${ }^{24}$. The difference between diPGLa-H and kiadin ${ }^{15} \mathrm{~N}$ chemical shifts compared to the random coil values ${ }^{24}$ (Fig. 5C) supported a helical stretch but also showed some differences from residue "Lys and, in particular, a strong ${ }^{15} \mathrm{~N}$ downfield shift in Kiadin for residues "le and ${ }^{16} \mathrm{Ala}$.
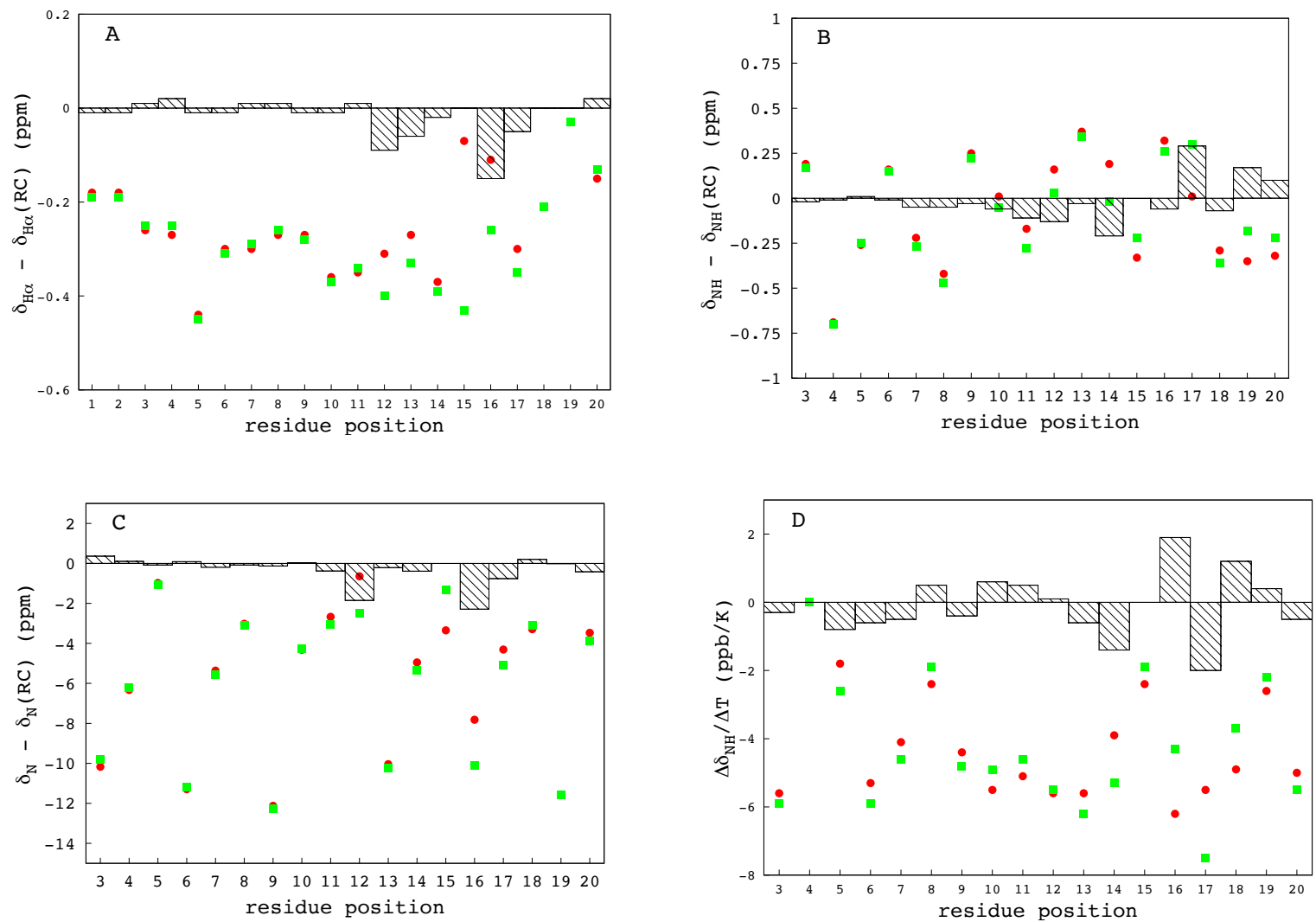

Figure 5 Conformational comparison based on NMR analysis of diPGLa-H (green squares) versus Kiadin (red circles) residues in the presence of SDS micelles at $50^{\circ} \mathrm{C}$ : (A) $\mathrm{H \alpha}$ chemical shift difference from random coil; (B) NH chemical shift difference from random 
coil; (C) ${ }^{i} \mathrm{~N}$ chemical shift differences from random coil; and (D) Amide $\mathrm{H}$ temperature coefficients obtained from $50^{\circ} \mathrm{C}$ down to $30^{\circ} \mathrm{C}$. The histograms represent the (A-C) chemical shift or (D) temperature coefficients difference between diPGLa-H and Kiadin, except for residue 15 .

The amide $\mathrm{H}$ chemical shifts showed a linear temperature dependence from $50^{\circ} \mathrm{C}$ down to $30^{\circ} \mathrm{C}$ (not shown). The amide $\mathrm{H}$ temperature coefficients displayed in Figure 5D can be used as an indicator for intramolecular hydrogen bond strength ${ }^{25}$ but can also indicate hydrogen bonds with the solvent and with the micelle ${ }^{26}$. Both peptides exhibited a similar range of coefficients, supporting high similitude in their helical secondary structure. In particular, ${ }^{4}$ Lys did not show any temperature dependence; residues ${ }^{5} \mathrm{Val},{ }^{\mathrm{s}} \mathrm{Lys},{ }^{\mathrm{s}} \mathrm{Gly} / \mathrm{Val}$ and ${ }^{\circ} \mathrm{Ala}$ showed coefficients in the range $-3<\Delta \delta_{\mathrm{NH}} / \Delta \mathrm{T}<0 \mathrm{ppb} / \mathrm{K}$ indicating strong intramolecular hydrogen bonds; residues ${ }^{2} \mathrm{Leu},{ }^{9} \mathrm{Ala}$, "Lys, ${ }^{4} \mathrm{Lys},{ }^{8} \mathrm{Lys}$ and ${ }^{2} \mathrm{Leu}$ coefficients were in the range $-5<$ $\Delta \delta_{\mathrm{вн}} / \Delta \mathrm{T}<-3 \mathrm{ppb} / \mathrm{K}$ indicating weak or solute-solvent hydrogen bonds; while all the others were below $-5 \mathrm{ppb} / \mathrm{K}$, which would exclude existence of stable hydrogen bonds. Note, however, that many exceptions to this evaluation exist and more complicated analyses, such as correlating the $\mathrm{NH}$ chemical shift difference and temperature coefficient ${ }^{27}$, may provide greater confidence in determining the strength of the hydrogen bonds in short linear peptides. Nevertheless, again the greatest differences between diPGLa-H and Kiadin amide proton temperature coefficients were observed near residue 15, from residue 14 to residue 18 (Fig. $6 B)$.

Overall, the glycine substitution promoted greater instability in the helical stretch and hydrogen bond strength, which may be related to the weakened antimicrobial activity, although the hydrophobic/hydrophilic surface did not appear to be drastically different in 
Kiadin. This is in contrast to the results for maculatin 1.1 where Mac P15G showed greater activity than Mac P15A and illustrates the point that the details of the peptide structure are important for AMP activity.

\section{Conclusions}

The rational design of more potent antimicrobial peptides has been attempted for decades, in particular using mutation studies that modulate the amphipathic structure of helical peptides. Even a small modification may affect peptide activity and there are many reports of AMPs with high homology but with different modes of interaction with lipid membranes ${ }^{28}$ and differing activities ${ }^{29}$. The present work showed that a single substitution of Gly for Val at position 15 resulted in a small difference in antimicrobial activity: mainly, Kiadin was less active against S. aureus ATCC 43300 (MRSA) as was reported previously ' but to a lesser extent for another MRSA strain. While CD showed that both peptides were mainly helical in the presence of lipid micelles, high-resolution NMR revealed subtle differences at the Cterminus due to Gly substitution leading to instability in the helical stretch and hydrogen bond strength in Kiadin but without greatly perturbing its amphipathic nature. This may indicate that reducing the helical stretch of AMPs may be detrimental to their activity.

\section{Supporting Information Description}

Figure S1. NOESY spectra of Kiadin

Figure S2. NOESY spectra of DiPGLa-H

Figure S3. HSQC spectra of Kiadin and DiPGLa-H

Table S1 and S2. Chemical shifts (ppm), hydrogen bond strengths and temperature coefficients of Kiadin and diPGLa-H in SDS micelles 
Table S3. Statistical information for the Kiadin and diPGLa-H NMR structures in SDS micelles

\section{Acknowledgment}

The authors acknowledge funding from the Australian Research Council for DP140102127 grant awarded to F.S.

\section{References}

1. Matsuzaki, K., Control of cell selectivity of antimicrobial peptides. Biochimica et Biophysica Acta 2009, 1788, 1687-92.

2. Araki, K.; Tachibana, S.; Uchiyama, M.; Nakajima, T.; Yasuhara, T., Isolation and structure of a new active peptide "Xenopsin" on the smooth muscle, especially on a strip of fundus from a rat stomach, from the skin of Xenopus laevis. Chemical \& Pharmaceutical Bulletin 1973, 21, 2801-4.

3. Hou, F.; Li, J.; Pan, P.; Xu, J.; Liu, L.; Liu, W.; Song, B.; Li, N.; Wan, J.; Gao, H., Isolation and characterisation of a new antimicrobial peptide from the skin of Xenopus laevis. International Journal of Antimicrobial Agents 2011, 38, 510-5.

4. Glattard, E.; Salnikov, E. S.; Aisenbrey, C.; Bechinger, B., Investigations of the synergistic enhancement of antimicrobial activity in mixtures of magainin 2 and PGLa. Biophysical Chemistry 2016, 210, 35-44.

5. Salnikov, E. S.; Aisenbrey, C.; Aussenac, F.; Ouari, O.; Sarrouj, H.; Reiter, C.; Tordo, P.; Engelke, F.; Bechinger, B., Membrane topologies of the PGLa antimicrobial peptide and a transmembrane anchor sequence by Dynamic Nuclear Polarization/solid-state NMR spectroscopy. Scientific Reports 2016, 6, 20895.

6. Juretic, D.; Vukicevic, D.; Ilic, N.; Antcheva, N.; Tossi, A., Computational design of highly selective antimicrobial peptides. Journal of Chemical Information and Modeling 2009, 49, 2873-82.

7. Roncevic, T.; Gajski, G.; Ilic, N.; Goic-Barisic, I.; Tonkic, M.; Zoranic, L.; Simunic, J.; Benincasa, M.; Mijakovic, M.; Tossi, A.; Juretic, D., PGLa-H tandem-repeat peptides active against multidrug resistant clinical bacterial isolates. Biochimica et Biophysica Acta 2017, 1859, 228-237.

8. Fernandez, D. I.; Lee, T. H.; Sani, M. A.; Aguilar, M. I.; Separovic, F., Proline facilitates membrane insertion of the antimicrobial peptide maculatin 1.1 via surface indentation and subsequent lipid disordering. Biophysical Journal 2013, 104, 1495-507. 9. Pace, C. N.; Scholtz, J. M., A helix propensity scale based on experimental studies of peptides and proteins. Biophysical Journal 1998, 75, 422-7.

10. Marion, D.; Wuthrich, K., Application of phase sensitive two-dimensional correlated spectroscopy (COSY) for measurements of $1 \mathrm{H}-1 \mathrm{H}$ spin-spin coupling 
constants in proteins. Biochemical and Biophysical Research Communications 1983, 113, 967-74.

11. Cheung, M. S.; Maguire, M. L.; Stevens, T. J.; Broadhurst, R. W., DANGLE: A Bayesian inferential method for predicting protein backbone dihedral angles and secondary structure. Journal of Magnetic Resonance 2010, 202, 223-33.

12. Bechinger, B.; Zasloff, M.; Opella, S. J., Structure and dynamics of the antibiotic peptide PGLa in membranes by solution and solid-state nuclear magnetic resonance spectroscopy. Biophysical Journal 1998, 74, 981-7.

13. Kyte, J.; Doolittle, R. F., A simple method for displaying the hydropathic character of a protein. Journal of Molecular Biology 1982, 157, 105-32.

14. Durr, U. H.; Sudheendra, U. S.; Ramamoorthy, A., LL-37, the only human member of the cathelicidin family of antimicrobial peptides. Biochimica et Biophysica Acta 2006, $1758,1408-25$.

15. Sani, M. A.; Separovic, F., How Membrane-Active Peptides Get into Lipid Membranes. Accounts of Chemical Research 2016, 49, 1130-8.

16. Sani, M. A.; Whitwell, T. C.; Separovic, F., Lipid composition regulates the conformation and insertion of the antimicrobial peptide maculatin 1.1. Biochimica et Biophysica Acta 2012, 1818, 205-11.

17. Marin-Medina, N.; Ramirez, D. A.; Trier, S.; Leidy, C., Mechanical properties that influence antimicrobial peptide activity in lipid membranes. Applied Microbiology and Biotechnology 2016, 100, 10251-10263.

18. Powers, J. P.; Hancock, R. E., The relationship between peptide structure and antibacterial activity. Peptides 2003, 24, 1681-91.

19. Wieprecht, T.; Apostolov, O.; Beyermann, M.; Seelig, J., Membrane binding and pore formation of the antibacterial peptide PGLa: thermodynamic and mechanistic aspects. Biochemistry 2000, 39, 442-52.

20. Chou, J. J.; Kaufman, J. D.; Stahl, S. J.; Wingfield, P. T.; Bax, A., Micelle-induced curvature in a water-insoluble HIV-1 Env peptide revealed by NMR dipolar coupling measurement in stretched polyacrylamide gel. Journal of the American Chemical Society 2002, 124, 2450-1.

21. Wishart, D. S.; Bigam, C. G.; Yao, J.; Abildgaard, F.; Dyson, H. J.; Oldfield, E.; Markley, J. L.; Sykes, B. D., 1H, 13C and 15N chemical shift referencing in biomolecular NMR. Journal of Biomolecular NMR 1995, 6, 135-40.

22. Andersen, N. H.; Liu, Z.; Prickett, K. S., Efforts toward deriving the CD spectrum of a 3(10) helix in aqueous medium. FEBS Letters 1996, 399, 47-52.

23. Popov, E. M.; Zheltova, V. N., Electronic structure and properties of the peptide group. J. Mol. Struc. 1971, 10, 221-230.

24. Wang, Y.; Jardetzky, O., Probability-based protein secondary structure identification using combined NMR chemical-shift data. Protein Science 2002, 11, 852-

61.

25. Tomlinson, J. H.; Williamson, M. P., Amide temperature coefficients in the protein G B1 domain. Journal of Biomolecular NMR 2012, 52, 57-64.

26. De Luca, S.; Ragone, R.; Bracco, C.; Digilio, G.; Aloj, L.; Tesauro, D.; Saviano, M.; Pedone, C.; Morelli, G., A cyclic CCK8 analogue selective for the cholecystokinin type A receptor: design, synthesis, NMR structure and binding measurements. ChemBioChem 2003, 4, 1176-87.

27. Andersen, N. H.; Neidigh, J. W.; Harris, S. M.; Lee, G. M.; Liu, Z.; Tong, H., Extracting information from the temperature gradients of polypeptide $\mathrm{NH}$ chemical shifts. 1 . The importance of conformational averaging. J. Am. Chem. Soc. 1997, 119, 8547-8561. 
28. Resende, J. M.; Verly, R. M.; Aisenbrey, C.; Cesar, A.; Bertani, P.; Pilo-Veloso, D.; Bechinger, B., Membrane interactions of phylloseptin-1, -2 , and -3 peptides by oriented solid-state NMR spectroscopy. Biophysical Journal 2014, $107,901-11$.

29. Resende, J. M.; Moraes, C. M.; Prates, M. V.; Cesar, A.; Almeida, F. C.; Mundim, N. C.; Valente, A. P.; Bemquerer, M. P.; Pilo-Veloso, D.; Bechinger, B., Solution NMR structures of the antimicrobial peptides phylloseptin-1, -2 , and -3 and biological activity: the role of charges and hydrogen bonding interactions in stabilizing helix conformations.

Peptides 2008, 29, 1633-44. 
ToC Graphic

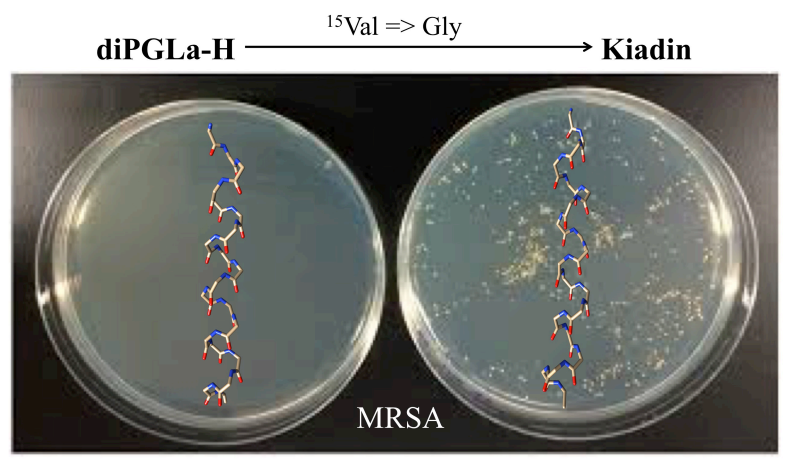

